\title{
Control of Basal Insulin Secretion, with Special Reference to the Diagnosis of Insulinomas
}

\author{
R. C. TURNER, N. W. OAKLEY, J. D. N. NABARRO
}

British Medical fournal, 1971, 2, 132-135

\begin{abstract}
Summary
Estimation of plasma glucose and immunoreactive insulin concentrations in normal subjects after an overnight fast showed that subjects with high basal plasma glucose levels tended to have high plasma insulin concentrations. A similar correlation between glucose and insulin levels was seen in patients with obesity and various endocrine disorders. The suppression of plasma insulin levels associated with hypoglycaemia was used to derive an "amended insulin-glucose ratio," which appeared to be a good discriminant for the diagnosis of insulinomas. In normal subjects the ratio was less than $30 \mu \mathrm{U}$ insulin/mg glucose, in obese subjects less than $50 \mu \mathrm{U} / \mathrm{mg}$, and most of the patients with insulinomas had values over $200 \mu \mathrm{U} / \mathrm{mg}$.
\end{abstract}

\section{Introduction}

The role of the basal insulin secretion in determining the fasting plasma glucose concentration is uncertain, as is the extent to which the fasting glucose concentration controls the basal insulin secretion. A constant glucose infusion which increases the plasma glucose by $10 \mathrm{mg} / 100 \mathrm{ml}$ increases the plasma insulin concentration (Goodner et al., 1969); this suggests that small increases in plasma glucose can increase plasma insulin levels, but does not determine to what extent the basal insulin secretion itself is regulated by the plasma glucose concentration. The fasting insulin secretion is unlikely to be a minimal, inevitable level of secretion, as the plasma insulin falls with fasting and exercise (Cahill et al., 1966; Hunter, 1969). Though the plasma glucose concentration may control basal insulin secretion, it is unlikely to be the only operative factor, as is shown by the high basal insulin levels of obese subjects (Karam et al., 1963; Perley and Kipnis, 1966) and of subjects with acromegaly (Sönksen et al., 1967).

The relationship of the fasting plasma insulin level to the fasting plasma glucose has been examined in normal subjects and in patients with various endocrine disorders. This relationship has been particularly examined in patients with insulinomas, with a view to formulating an improved discriminant for the diagnosis of this condition (Grunt et al., 1970).

Insulinomas are sometimes difficult to diagnose; patients characteristically have fasting hypoglycaemia, and the diagnosis is usually confirmed by demonstrating an excessive insulin response to stimuli such as tolbutamide, leucine, or glucagon. These tests are, however, not very satisfactory, and false-positive and false-negative results can be obtained (Fajans, 1969; Marks and Samols, 1969). In general, auto-

Institute of Clinical Research, Middlesex Hospital, London W.1 R. C. TURNER, M.C.R.P., Leverhulme Research Fellow (Present address: Massachusetts General Hospital, Boston, U.S.A.)

J. D. N. NABARRO, M.D., F.R.C.P., Director

Alexander Simpson Laboratory, St. Mary's Hospital, London W.2

N. W. OAKLEY, M.R.C.P., Lecturer in Human Metabolism nomous endocrine function is more easily diagnosed by suppressive rather than stimulatory tests (compare dexamethasone test in Cushing's syndrome, triiodothyronine in thyrotoxicosis, and glucose in acromegaly). The same principle can be applied to insulinomas; if the fasting plasma glucose level controls insulin secretion one might expect that in normal subjects hypoglycaemia would suppress insulin secretion, whereas there might be lack of suppression in subjects with insulinomas. Thus although fasting plasma insulin levels of patients with insulinomas may be within the normal range, they might be expected to be inappropriate in relation to the prevailing glucose concentration.

\section{Patients and Methods}

Blood samples were obtained from two groups of normal subjects (38 and 49 persons respectively) after an overnight fast. Most of the first group and all of the second group had come to hospital on the morning of the test; some of the first group were inpatients; all had rested for at least 30 minutes before blood sampling. The first group were aged 18-24 and were within $10 \%$ of ideal body weight; the second group were all premenopausal women, not receiving oral contraceptives, with no family history of diabetes, and within $15 \%$ of ideal body weight. All subjects had normal oral or intravenous glucose tolerance. Eleven obese subjects who were more than $33 \%$ over their ideal body weight, and who had normal oral or intravenous glucose tolerance, were studied. Ten patients with untreated acromegaly, seven patients with untreated Cushing's syndrome, and 11 patients with anterior pituitary deficiency were also studied. The hypopituitary patients all had basal growth hormone levels less than $1 \mathrm{ng} / \mathrm{ml}$, and after insulininduced hypoglycaemia (with a blood sugar nadir of less than $40 \mathrm{mg} / 100 \mathrm{ml}$ ) had a rise in growth hormone of $2 \mathrm{ng} / \mathrm{ml}$ or less. Six of these patients appeared to have deficient ACTH production (with a 9 a.m. plasma cortisol of $10 \mu \mathrm{g} / \mathrm{ml}$ or less, and a rise of $4 \mu \mathrm{g} / \mathrm{ml}$ or less after insulin-induced hypoglycaemia. The other five had a 9 a.m. cortisol level of at least $8 \mu \mathrm{g} / \mathrm{ml}$, and a rise in response to hypoglycaemia of at least $10 \mu \mathrm{g} / \mathrm{ml}$.

Five subjects were studied in whom an insulinoma was later diagnosed at operation. Two subjects who were thought to have insulinomas, but who were well controlled on diazoxide and did not have operations, were also investigated; both were moderately obese middle-aged women with symptomatic fasting hypoglycaemia; neither had an overt cause-such as liver disease, pituitary/adrenal insufficiency, or a large tumourfor their hypoglycaemia.

Plasma immunoreactive insulin has been measured by the method of Albano et al (1971). The method is probably more accurate in measuring low plasma insulin levels than are many other assay systems (Cotes et al., 1969) and gives identical results for serum and plasma. The basal plasma insulin of normal subjects contains a large proportion of proinsulin (Melani et al., 1970b); the degree to which proinsulin crossreacts with the antisera used by the two centres in the present investigation is not known. Plasma glucose has been measured with two ortho-tolidine-glucose oxidase autoanalyser methods, the first group using the method of Marks and Lloyd (1963) and the second group that of Cramp (1967). 


\section{Results}

The correlation between plasma glucose and insulin for both groups of normal subjects is shown in Fig. 1; the patterns are almost identical, and subjects with high plasma glucose levels tend to have high insulin levels.

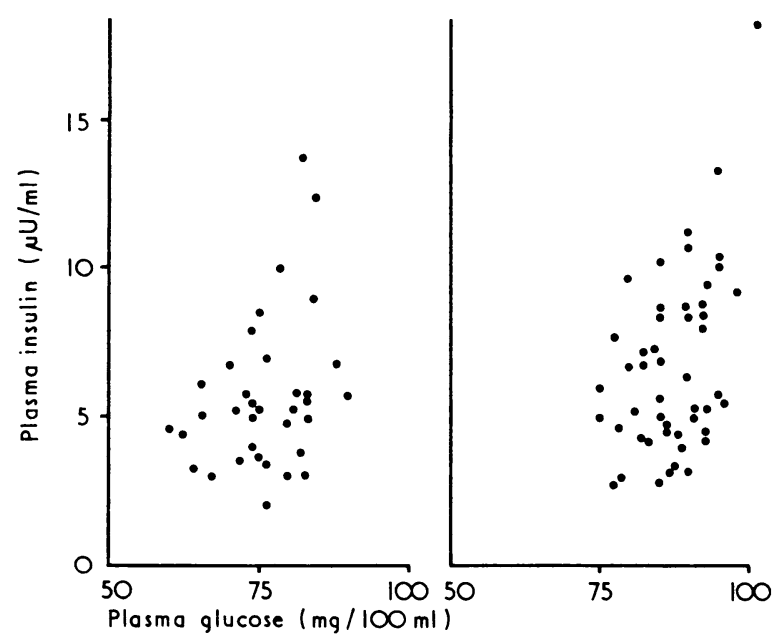

FIG. 1-Plasma insulin-glucose relationships in normal subjects following an overnight fast. (Left, Middlesex Hospital series. Right, St. Mary's Hospital series.)

The fasting plasma insulin levels, and their relationship to plasma glucose concentrations, of the subjects with obesity and endocrine disorders are shown in Figs. 2 and 3. The subjects with obesity, acromegaly, and Cushing's syndrome tend to have high basal plasma glucose and insulin levels. The hypopituitary patients have low fasting plasma glucose levels, and those with deficient cortisol production tend to have low plasma insulin levels.

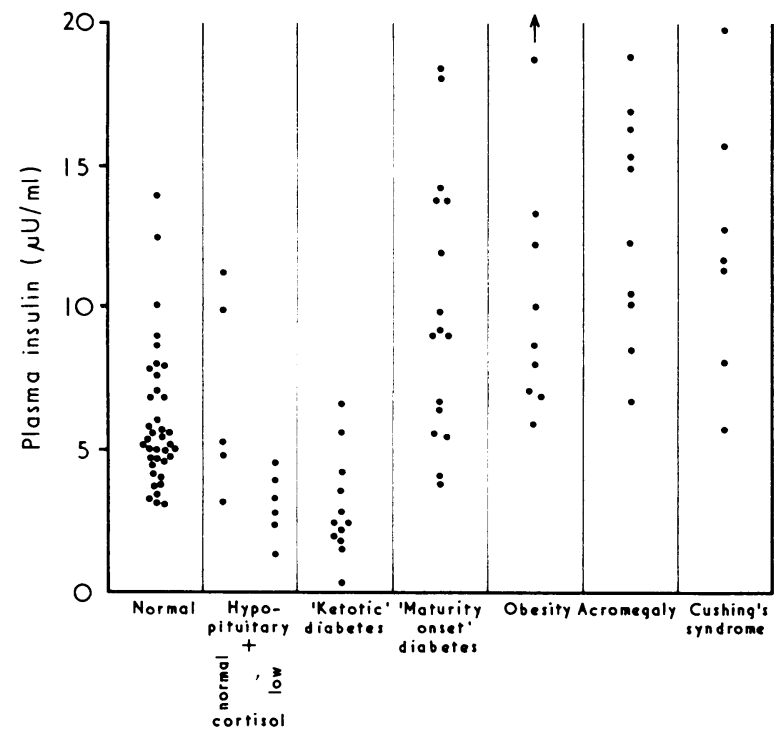

FIG. 2-Fasting plasma insulin values in normal and obese subjects and patients with various endocrine disorders.

The fasting plasma insulin levels of the patients with proved or suspected insulinomas can be within the normal range (Fig. 4). If, however, the insulin levels are examined in relation to the plasma glucose concentrations the ratios for these patients are usually outside the normal range (Fig. 5). Separation of normal from insulinoma patients can be improved still

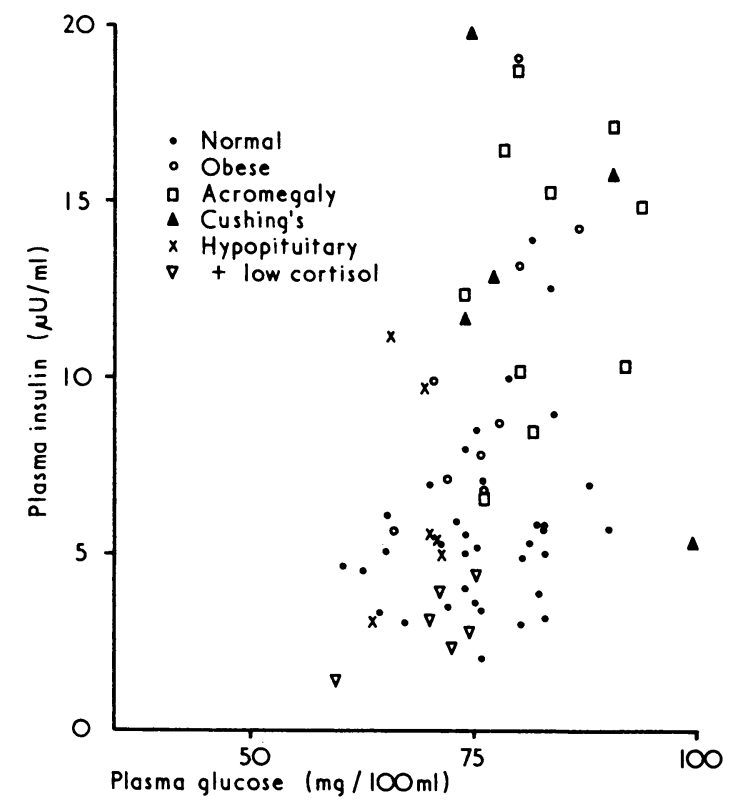

FIG. 3-Plasma insulin-glucose relationships in normal and obese subjects and patients with various endocrine disorders.

further by using a discriminant based on the observation (Turner et al., 1971) that the plasma insulin levels of normal subjects are near zero if the plasma glucose is $30 \mathrm{mg} / 100 \mathrm{ml}$ or less. This discriminant, obtained by evaluating the expression plasma insulin $(\mu \mathrm{U} / \mathrm{ml}) \times 100$

plasma glucose $(\mathrm{mg} / 100 \mathrm{ml})-30$

has been called the "amended insulin-glucose ratio" (Fig. 6).

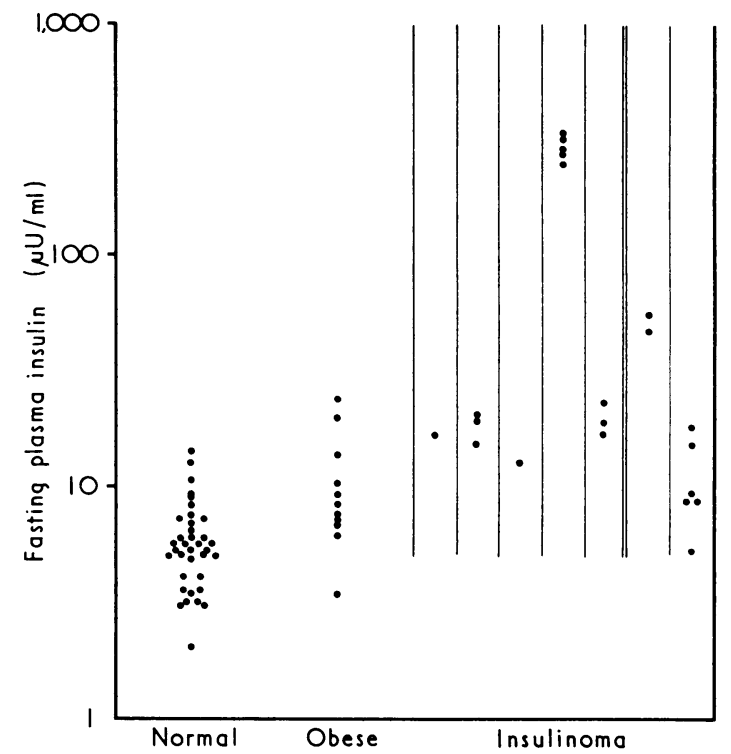
FIG. 4-Fasting plasma insulin values in normal and obese subjects and
patients with insulinomas. For insulinoma patients points within each ruled patients with insulinomas. For insulinoma patients points within each ruled
column represent values on different days for the same subject. The two column represent values on different days for the same subject. The two
patients to the right of the double line have not been subjected to surgery.

The amended ratio of normal subjects gives a value of less than $30 \mu \mathrm{U} / \mathrm{mg}$. Obese subjects have raised plasma insulin levels but the amended insulin-glucose ratio is usually below $50 \mu \mathrm{U} / \mathrm{mg}$. Obese subjects with high plasma insulin values usually have plasma glucose concentrations of more than $75 \mathrm{mg} / 100 \mathrm{ml}$, and there is little risk of an erroneous diagnosis of insulinoma being made on account of a high insulin-glucose ratio. All proved cases of insulinoma have amended ratios of 


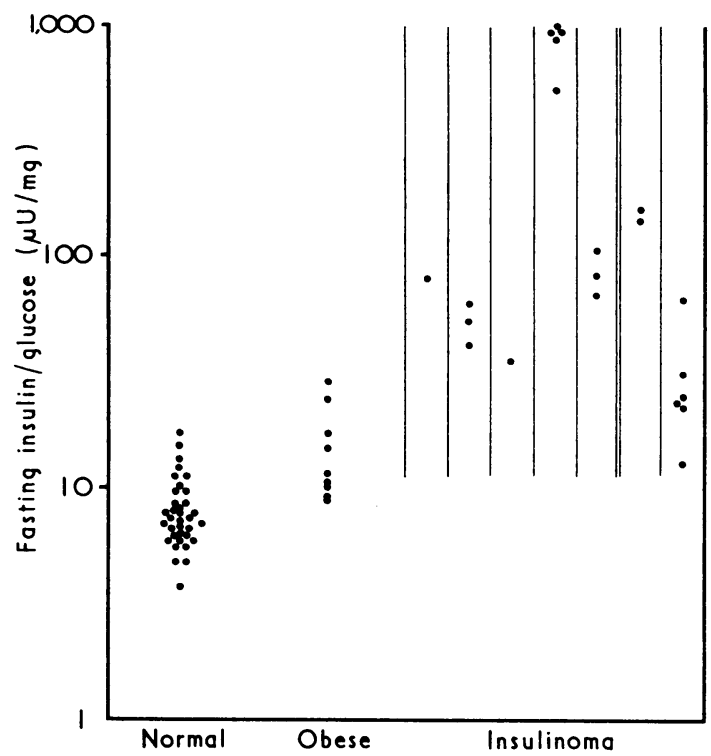

FIG. 5-Fasting insulin-glucose ratios for normal and obese subjects, and patients with insulinomas. Details as for Fig. 4.

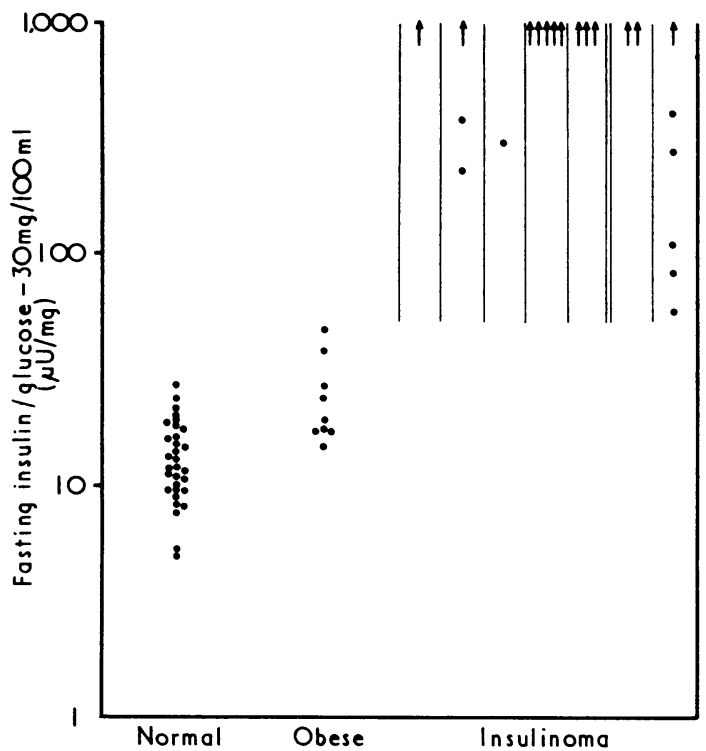

FIG. 6-"Amended insulin-glucose ratios" (see text) for normal and obese subjects and patients with insulinomas. Details as for Fig. 4.

more than $200 \mu \mathrm{U} / \mathrm{mg}$, though one of the patients in whom the diagnosis was suspected, but not proved, had ratios on different days varying between 55 and $400 \mu \mathrm{U} / \mathrm{mg}$. Patients with low fasting plasma glucose values due to hypopituitary disorders have normal amended ratios.

The amended insulin-glucose ratio is a means of applying a tangible figure to the glucose-insulin relationship, but equally useful information can be obtained by plotting the raw data directly on a graph of the two criteria (Fig. 7).

\section{Discussion}

The plasma insulin levels of normal fasting subjects span a five-fold range. There is a correlation between fasting plasma insulin and glucose concentrations in normal subjects, and the

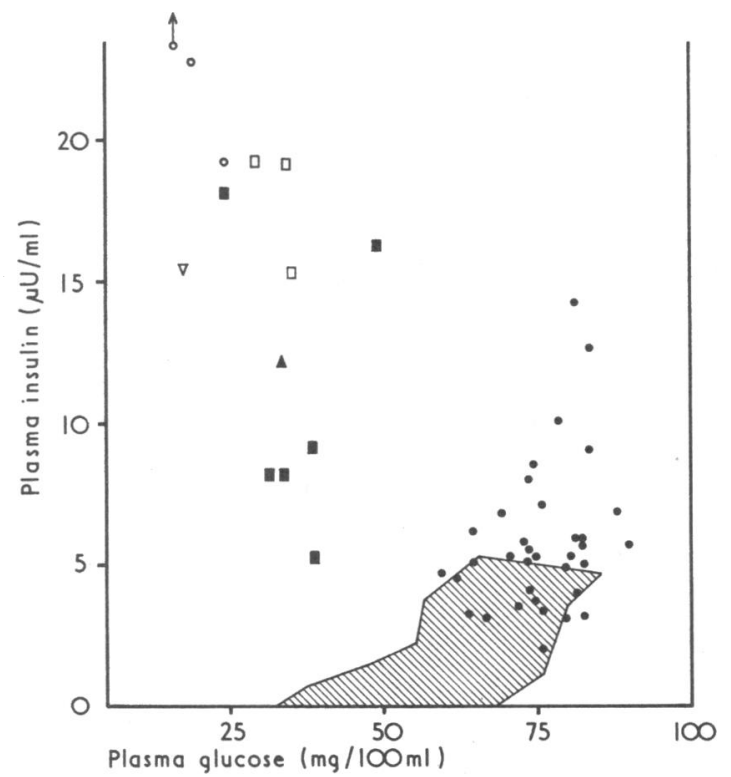

FIG. 7-Fasting plasma insulin-glucose relationships in normal subjects and patients with proved or suspected insulinomas. Small closed circles represent normal subjects. Other symbols each represent one insulinoma patient. Hatched area shows normal range during ethanol infusion (Turner et al., 1971).

relationship between plasma glucose and insulin levels in patients with endocrine disorders is an extension of this trend. This suggests that the fasting plasma insulin is not the main determinant of the fasting plasma glucose, for if this were the case the patients with high plasma insulin levels would tend to have low plasma glucose values. Different normal subjects have variable hypoglycaemic responses to a standard dose of insulin and differing degrees of insulin sensitivity (Martin et al., 1968); it seems likely that insulin resistance and factors other than insulin, which control glucose homoeostasis, are important in determining the fasting glucose concentration. Studies in which arterial blood glucose has been measured at 30 -second intervals, in the fasting state, show that oscillations about the mean value, with a cycle length of two to six minutes, occur both in normal subjects and in growth onset diabetic patients, given their last injection of long-acting insulin about 12 hours before the experiment. These results were interpreted as suggesting that insulin is not important for short-term blood glucose homoeostasis (Deckert and Ege, 1970).

Though there is a correlation between plasma glucose and insulin levels, there may not be a causal relationship, and it is possible that factors which regulate the basal plasma glucose may also control basal insulin secretion. There is evidence that there may be an enzyme system in the beta-cell which can be induced by increased glucose availability (Grey et al., 1970) and it is possible that hormone factors may regulate beta-cell function by directly affecting intracellular enzyme activity or substrate concentrations. Obese subjects with normal glucose tolerance have raised blood levels of certain amino-acids (Felig et al., 1969), and amino-acids are "known to act synergistically with glucose in stimulating insulin release (Floyd et al., 1965). It has been postulated that these raised amino-acid levels could be a factor stimulating the increased basal insulin secretion of obese subjects.

It seems that the relationship between the fasting glucose and insulin levels can be used as a means of diagnosing insulinomas. Patients with insulinomas perform a "suppression test" on themselves when fasting. Examination of fasting glucose-insulin relationships has recently been proposed by other workers (Grunt et al., 1970); however, they determined a direct insulin-glucose ratio, rather than the "amended" ratio used in the present study, and the latter would appear to be 
a logical approach. If an insulinoma is suspected a means of confirming the diagnosis would be to take three morning plasma samples after an overnight fast. In a subject who has fasting hypoglycaemia an amended ratio of more than $50 \mu \mathrm{U} /$ $\mathrm{mg}$, in the absence of very severe obesity, is strongly suggestive of an insulinoma, and a ratio of more than $200 \mu \mathrm{U} / \mathrm{mg}$ would appear to be diagnostic. Very occasionally patients with extreme obesity, pregnancy, or liver disease with a portosystemic shunt might give "false-positive" results; in most doubtful cases an ethanol infusion could be performed as described elsewhere (Turner et al., 1971).

It has recently been shown that insulinomas secrete a high proportion of proinsulin (Melani et al., 1970a). This does not invalidate the examination of fasting insulin levels as a diagnostic measure, as a high level of immunoreactive insulin relative to the plasma glucose is the diagnostic feature-any cross-reacting proinsulin from an insulinoma would exaggerate an abnormal ratio.

We wish to thank the nursing staff of the Middlesex Hospital for their continued help; Professor V. Wynn for allowing us to investigate patients under his care, and for his advice and encouragement; Miss B. Schneeloch for technical assistance; the University of London Central Research Fund for providing the Technicon AutoAnalyzer at the Middlesex Hospital; the British Diabetic Association for grants to cover technical assistance; and Dr. Julia Ellis for anti-insulin serum (GP5).

\section{References}

Albano, J., Elkins, R. P., Maritz, G. G., and Turner, R. C. (1971). In

Cahill, G. F., et al. (1966). Fournal of Clinical Investigation, 45, 1751.

Cotes, P. M., et al. (1969). Fournal of Endocrinology, 45, 557.

Cramp, D. G. (1967). Fournal of Clinical Pathology, 20, 910.

Deckert, T., and Ege, P. (1970). Acta Medica Scandinavica, 187, 331.

Fajans, S. S. (1969). Excerpta Medica, International Congress Series, No. 172 , p. 894.

Felig, P., Marliss, E., and Cahill, G. F. (1969). New England fournal of Medicine, 281, 811 .

Floyd, J. C., Fajans, S. S., Knopf, R. F., Rull, J., and Conn, J. W. (1965). Clinical Research, 13, 322.

Goodner, C. J., Conway, M. J., and Werrbach, J. H. (1969). Fournal of Clinical Investigation, 48, 1878.

Grey, N. J., Goldring, S., and Kipnis, D. M. (1970). Fournal of Clinical Investigation, 49, 881 .

Grunt, J. A., Pallotta, J. A., and Soeldner, J. S. (1970. Diabetes, 19, 122. Hunter, W. M. (1969). Excerpta Medica, International Congress Series, No. 161, p. 551 .

Karam, J. H., Grodsky, G. M., and Forsham, P. H. (1963). Diabetes, 12, 197.

Marks, $\dot{V}_{\text {., and Lloyd, K. (1963). Proceedings of the Association of Clinical }}$ Biochemists, 2, 176

Marks, V., and Samols, S. (1969). Excerpta Medica, International Congress Series, No. 172, 864.

Martin, F. I. R., Pearson, M. J., and Stocks, A. E. (1968). Lancet, 1, 1285. Melani, F., Oyer, P., Rubenstein, A. H., and Steiner, D. F. (1970a). Excerpto Medica, International Congress Series, 209, p. 2 .

Melani, F., Rubenstein, A. H., and Steiner, D. F. (1970b). fournal of Clinical Investigation, 49, 497.

Investigation, 49, 497.
Perley, M., and Kipnis, D. M. (1966). Diabetes, 15, 867.

Sönksen, P. H., et al. (1967). Fournal of Clinical Endocrinology and Metabolism, 27, 1418

Turner, R. C., Oakley, N. W., and Nabarro, J. D. N. (1971). In press.

\title{
Pericarditis after Acute Myocardial Infarction
}

\author{
U. THADANI, M. P. CHOPRA, CLIVE P. ABER, R. W. PORTAL
}

British Medical fournal, 1971, 2, 135-137

\section{Summary}

Fifty-two (6.8\%) of 779 patients admitted to a coronary monitoring unit with acute myocardial infarction developed a pericardial friction rub. A diagnosis of postmyocardial infarction syndrome was made in three of these.

The course of the 52 patients with pericarditis was compared with that of a consecutive series of 100 patients without pericarditis. As a group those with pericarditis manifested a longer period of pyrexia, a greater rise in serum enzymes, and a higher incidence of major arrhythmias and of radiological pulmonary oedema. The Peel prognostic index, however, did not differ significantly in the two groups. The hospital mortality of the pericarditis group was not significantly different from that of the 727 non-pericarditis patients. No specially adverse features were found in a follow-up of the pericarditis group.

Though the presence of a pericardial rub in the first few days after a myocardial infarction may be a sign of extensive myocardial damage and is associated with a relatively high incidence of ventricular fibrillation, it does not appear to influence the hospital mortality of patients treated in a monitoring unit.

Department of Cardiology, Kingston General Hospital, Hull HU3 IUR U. THADANI, M.B., M.R.C.P., Registrar

M. P. CHOPRA, M.B., B.S., Research Assistant (Recipient of Research Grant from Leeds Regional Hospital Board)

CLIVE P. ABER, M.D., M.R.C.P., Consultant Physician

R. W. PORTAL, M.D., M.R.C.P., Consultant Physician

\section{Introduction}

A pericardial rub is a common physical sign after acute myocardial infarction. Since, however, it is usually a transient phenomenon it is often regarded as an incidental finding, hardly ranking as a complication. The pericarditis of the postmyocardial infarction syndrome commonly develops later in the illness, is more prolonged, may be recurrent, and was estimated by Dressler (1959) as occurring in 3 to $4 \%$ of cases.

Since the establishment of coronary care units no further clinical observations appear to have been made about this relatively common feature of acute myocardial infarction. The present study was therefore undertaken to determine the incidence of clinically recognizable pericarditis after acute infarction, and to establish whether its occurrence carried any immediate or long-term prognostic significance.

\section{Patients and Methods}

The 52 patients studied were among 779 (593 men and 186 women) with acute myocardial infarction admitted to a coronary monitoring unit between October 1967 and July 1970. The organization of the unit has been described (Aber et al., 1969). The diagnosis of infarction was based on a characteristic history, together with electrocardiographic evidence (World Health Organization (1959) criteria) and/or a significant rise of serum aspartate aminotransferase (glutamic oxaloacetic transaminase, SGOT) and serum $\alpha$-hydroxybutyrate dehydrogenase. SGOT levels were measured by a modification of the method of Babson et al. (1962) and serum $\alpha$-hydroxybutyrate dehydrogenase by the method of Elliott and Wilkinson (1961). The serum enzymes were estimated daily for three consecutive days. 